\title{
When the timing is right: Antibiotic timing and infection after cardiac surgery
}

\author{
Colleen G. Koch, MD, MS, MBA, ${ }^{\text {a,b }}$ Edward R. Nowicki, MD, MS, ${ }^{c}$ Jeevanantham Rajeswaran, MSc, ${ }^{\mathrm{d}}$ \\ Steven M. Gordon, MD, ${ }^{\mathrm{e}}$ Joseph F. Sabik III, MD, ${ }^{\mathrm{c}}$ and Eugene H. Blackstone, MD ${ }^{\mathrm{c}, \mathrm{d}}$
}

\begin{abstract}
Objectives: Guidelines recommend antibiotic prophylaxis 60 minutes before skin incision; however, it is unclear whether more precise timing would further reduce sternal wound infection. Our objectives were to examine the relationship between antibiotic timing and infection, test potential efficacy of optimal antibiotic timing in preventing infection, and determine whether patient comorbidity is related to timing and infection.
\end{abstract}

Methods: From 1/1/1995-1/1/2008, 28,250 patients underwent 28,702 cardiac surgical procedures involving a median sternotomy; $85 \%$ received only cefuroxime and $15 \%$ received only vancomycin prophylaxis. Multivariable analysis identified factors associated with infection within each phase, and risk-adjusted optimal timing was determined using patient data, risk variables, and hypothetical values of antibiotic timing.

Results: Prevalence of sternal wound infection was $2.0 \%$ (489 patients) for cefuroxime and $2.3 \%$ (101 patients) for vancomycin. Minimum prevalence for infection was $1.8 \%$ observed when cefuroxime was administered 15 minutes before incision; risk increased to $2.2 \%$ with administration more than 45 minutes before incision and to $2.8 \%$ at 60 minutes before incision. Minimum prevalence of infection in patients who received vancomycin was $1.8 \%$ observed with initiation 32 minutes before incision; risk increased to $2.2 \%$ for administration 45 minutes before incision and 3.2\% with administration 60 minutes before incision. Simulation for optimal timing found that it was influenced by phase-specific risk factors.

Conclusions: Refining current antibiotic prophylaxis guidelines may lower sternal wound infections. Antibiotic administration timing resulting in lowest likelihood for infection varied with antibiotic and patient-specific factors. Optimal risk-adjusted timing could potentially reduce infections by 9\%-31\%. (J Thorac Cardiovasc Surg 2012;144:931-7)

Supplemental material is available online.

Safety for the 30 million Americans who undergo surgical procedures annually is at the heart of strategies for preventing surgical site infections. There are guidelines for proper choice, timing of administration, and duration of prophylactic antibiotics in cardiac surgery, of which optimal timing of antibiotic administration has been the most problematic to define. Previous studies have identified the importance of

\footnotetext{
From the Department of Cardiothoracic Anesthesiology, ${ }^{a}$ Anesthesiology Institute, Quality and Patient Safety Institute, ${ }^{\mathrm{b}}$ Department of Thoracic and Cardiovascular Surgery, ${ }^{\mathrm{c}}$ Heart and Vascular Institute, Department of Quantitative Health Sciences, ${ }^{\mathrm{d}}$ Research Institute, and Department of Infectious Disease, ${ }^{\mathrm{e}}$ Medicine Institute, Cleveland Clinic, Cleveland, Ohio.

This study was supported in part by the Kenneth Gee and Paula Shaw, PhD, Chair in Heart Research, held by Dr. Blackstone.

Disclosures: Authors have nothing to disclose with regard to commercial support.

Received for publication June 6, 2011; revisions received Dec 1, 2011; accepted for publication Jan 25, 2012; available ahead of print May 18, 2012.

Address for reprints: Colleen G. Koch, MD, MS, MBA, Cleveland Clinic, 9500 Euclid Ave/J4-245, Cleveland, OH 44195 (E-mail: kochc@ccf.org). $0022-5223 / \$ 36.00$

Copyright (c) 2012 by The American Association for Thoracic Surgery doi:10.1016/j.jtcvs.2012.01.087
}

prophylactic administration of antibiotics within $60 \mathrm{~min}$ utes before skin incision; however, it is unclear whether more precise timing of administration within that period would be more effective in lowering occurrence of postoperative sternal wound infection. The primary objectives were to examine the relationship between timing of prophylactic antibiotic administration and occurrence of postoperative sternal wound infection and to test the potential efficacy of optimal timing for choice of antibiotic in preventing infection. Our secondary objective was to determine whether patient comorbidity was related to optimal timing of antibiotic administration and subsequent postoperative sternal wound infection.

\section{PATIENTS AND METHODS \\ Patients}

From January 1, 1995, to January 1, 2008, a total of 28,250 patients underwent 28,702 cardiac surgical procedures involving a median sternotomy at Cleveland Clinic. Patients who had active endocarditis, surgical approach without a median sternotomy, lacked documentation for antibiotic administration, had more than 1 operation on the same date, or who received antibiotics other than cefuroxime and vancomycin were excluded from the analysis (Figure E1). Two study groups consisted of 24,272 $(85 \%)$ patients who received only cefuroxime and $4430(15 \%)$ who received only vancomycin prophylaxis. Baseline characteristics and perioperative variables by antibiotic status are presented in Table 1. 


\section{Abbreviations and Acronyms \\ BMI = body mass index \\ $\mathrm{COPD}=$ chronic obstructive pulmonary disease \\ ITA $=$ internal thoracic artery \\ STS $=$ The Society of Thoracic Surgeons}

\section{Data}

Demographics and perioperative variables were extracted from the Cardiovascular Information Registry and timing of antibiotic administration from chart abstraction and the Cardiothoracic Anesthesia Registry electronic anesthesia record (Table 1). The Cleveland Clinic Institutional Review Board approved these registries for use in research, with patient consent waived.

Of note, our standard protocol for prophylaxis in cardiac surgical patients included administration of cefuroxime for non-penicillin-allergic patients ( $1.5 \mathrm{~g}$ every 12 hours $\times 3$ doses); penicillin-allergic patients received vancomycin prophylaxis ( $1 \mathrm{~g}$ every 12 hours $\times 3$ doses); subsequent to this study, in 2009 , aztreonam $1 \mathrm{~g} \times 1$ dose was added to the vancomycin regimen. Since 2003, we have used preoperative screening for Staphylococcus aureus carriage with use of mupirocin for decolonization, if positive. ${ }^{1}$ In addition, strict attention was directed toward control of perioperative blood sugar per standardized perioperative protocol. ${ }^{2}$

\section{End Point}

End points of the investigation were occurrence of deep and superficial sternal wound infection. Case ascertainment done for sternal wound infection was defined by The Society of Thoracic Surgeons (STS).

\section{Data Analysis}

Simple descriptive statistics were used to summarize the data: mean \pm standard deviation and $15 \mathrm{th} / 50 \mathrm{th} / 85$ th percentiles for continuous variables and frequencies and percentages for categorical variables. Comparisons were made using the Wilcoxon rank-sum tests and $\chi^{2}$ tests, respectively.

Because cefuroxime and vancomycin have different dosing administration times, all analyses for each were performed separately.

All analyses were performed using SAS statistical software (SAS v9.5, SAS, Inc, Cary, NC) and R statistical software. ${ }^{3}$

\section{Missing Data}

In this prospective observational data, many baseline variables have missing data, with the degree ranging from $0 \%$ to $17 \%$. Hence, to avoid eliminating the missing cases in the multivariable analyses, we have used completed data sets obtained by multiple imputation. It was performed using the Markov Chain Monte Carlo ${ }^{4}$ technique to impute missing values using 5-fold multiple imputation with PROC MI (SAS v9.1). In the logistic modeling, for each imputed data set, we estimated regression coefficients and their variance-covariance matrix. Following Rubin, ${ }^{4}$ we combined estimates from the 5 models using PROC MIANALYZE.

Temporal pattern of prevalence of infection. Using a nonlinear binary logistic regression, we first analyzed the temporal pattern of the prevalence over the timing of antibiotic (interval from time of incision to time of antibiotic administration). PROC NLMIXED (SAS, Inc) was used to identify the additive phases (of timing of antibiotic) in the odds domain. Asymmetric 68\% confidence intervals for prevalence of infection (equivalent to \pm 1 standard error) were obtained by the bootstrap percentile method. ${ }^{5}$

Multivariable analyses. Multivariable analysis of preoperative variables (Table 1) was performed to identify factors associated with infection within each phase (see Appendix E1 for details). Variable selection was performed using bootstrap bagging (bootstrap aggregation). ${ }^{6,7} \mathrm{At}$ each step of the aggregation, the original data set was sampled with replacement, and using stepwise selection with entry criterion of $P=.1$ and retention criterion of $P=.05$, variables associated with infection were identified and stored. These steps were repeated 500 times. All variables with bootstrap reliability of $50 \%$ or more were retained in the guided analysis.

Optimal timing. Optimal timing was defined as the time of antibiotic administration when the likelihood of sternal wound infection was lowest.

For each patient, risk-adjusted optimal timing was determined by solving the multivariable equations using that patient's actual data, the risk variables, and hypothetical values of antibiotic timing. We then obtained optimal timing by identifying the hypothetical time when the predicted risk of infection was lowest.

\section{RESULTS \\ Antibiotic Timing}

Overall, nearly $90 \%$ of patients received antibiotics within the protocol time frame. However, in the cefuroxime group, where the protocol is administration within $60 \mathrm{~min}-$ utes before incision, $4.6 \%$ received it too early and $3.8 \%$ too late. In the vancomycin group, where the protocol is administration within 120 minutes before incision, $0.61 \%$ received it too early and $10 \%$ too late (Figure 1).

\section{Sternal Wound Infection}

Overall prevalence of sternal wound infection was $2.1 \%$ (590 patients); superficial wound infection prevalence was $1.3 \%$ (379), and deep wound infection $0.74 \%$ (211). Inhospital mortality was higher among patients with a sternal wound infection than those without, $8.6 \%$ versus $1.8 \%$; $P<.0001$. Morbidity was substantially greater in patients with than without sternal wound infections: stroke, $4.1 \%$ versus $1.5 \%, P<.0001$; renal failure, $8.5 \%$ versus $1.4 \%$, $P<.0001$; respiratory insufficiency, $30 \%$ versus $6.1 \%$, $P<.001 ;$ and septicemia/sepsis, $26 \%$ versus $2.1 \%$, $P<.0001$, respectively. Similarly, median length of hospital stay was 17 days (15th and 85 th percentiles $=8$ and 36 days) for patients with sternal wound infections versus 6 days (15th and 85 th percentiles $=5$ and 11 days) for those without; $P<.0001$. Among patients who received cefuroxime alone, prevalence of sternal wound infection was $2.0 \%$ (489 patients); prevalence with vancomycin alone was $2.3 \%$ (101 patients), $P=.3$.

\section{Timing and Infection}

Cefuroxime. Unadjusted minimum prevalence for infection was $1.8 \%$ and observed when cefuroxime was administered 15 minutes before surgical incision (Figure 2). Predicted percentages of sternal wound infection varied considerably for antibiotic timing both within protocol guidelines and for protocol deviations (Table 2). Risk for sternal wound infection increased when cefuroxime was administered more than 15 minutes before surgical incision, yet within protocol recommendations. Prevalence of infection was $2.2 \%$ at 45 minutes and $2.8 \%$ at 60 minutes before skin incision. Protocol 
TABLE 1. Patient and perioperative characteristics by antibiotic status

\begin{tabular}{|c|c|c|c|c|}
\hline \multirow[b]{2}{*}{ Variable } & \multicolumn{2}{|c|}{ Vancomycin (total $n=\mathbf{4 , 4 3 0}$ ) } & \multicolumn{2}{|c|}{ Cefuroxime (total $n=24,272$ ) } \\
\hline & n* & No. $(\%)$ or mean \pm SD & $\mathbf{n}^{*}$ & No. $(\%)$ or mean \pm SD \\
\hline \multicolumn{5}{|l|}{ Demography } \\
\hline Age (y) & 4430 & $66 \pm 12$ & 24,272 & $65 \pm 12$ \\
\hline Male & 4430 & $2602(59)$ & 24,272 & $17,364(72)$ \\
\hline BMI $\left(\mathrm{kg} \cdot \mathrm{m}^{-2}\right)$ & 4426 & $28 \pm 5.7$ & 24,249 & $28 \pm 5.4$ \\
\hline \multicolumn{5}{|l|}{ Cardiac comorbidity } \\
\hline NYHA functional class III/IV & 4429 & $1613(36)$ & 24,268 & $7929(33)$ \\
\hline Emergency operation & 4430 & $82(1.9)$ & 24,272 & $326(1.3)$ \\
\hline Previous myocardial infarction & 4430 & $2011(45)$ & 24,271 & $11,145(46)$ \\
\hline Complete heart block/pacer (ECG) & 4430 & $186(4.2)$ & 24,272 & $816(3.4)$ \\
\hline Reoperation & 4430 & $1163(26)$ & 24,272 & $5540(23)$ \\
\hline \multicolumn{5}{|l|}{ Coronary artery disease $\dagger$} \\
\hline LAD & 3508 & $2416(69)$ & 19,359 & $14,005(72)$ \\
\hline $\mathrm{LCx}$ & 3504 & $2112(60)$ & 19,336 & $12,216(63)$ \\
\hline RCA & 3496 & $2194(63)$ & 19,321 & $12,685(66)$ \\
\hline LMT & 3497 & $690(20)$ & 19,328 & $3598(19)$ \\
\hline \multicolumn{5}{|l|}{ Noncardiac comorbidity } \\
\hline Peripheral arterial disease & 4430 & $2017(46)$ & 24,272 & $9716(40)$ \\
\hline COPD & 3927 & $1061(27)$ & 20,256 & $4527(22)$ \\
\hline Smoking & 4381 & $2631(60)$ & 23,996 & $14,285(60)$ \\
\hline Hypertension & 4332 & $3195(74)$ & 23,654 & $16,592(70)$ \\
\hline Treated diabetes & 4366 & $1204(28)$ & 23,770 & $5921(25)$ \\
\hline Dialysis & 3642 & $51(1.4)$ & 20,055 & $197(0.98)$ \\
\hline Stroke & 4430 & $416(9.4)$ & 24,272 & $1918(7.9)$ \\
\hline Bilirubin $\left(\mathrm{mg} \cdot \mathrm{dL}^{-1}\right)$ & 3683 & $0.71 \pm 0.56$ & 20,373 & $0.72 \pm 0.63$ \\
\hline Blood urea nitrogen $\left(\mathrm{mg} \cdot \mathrm{dL}^{-1}\right)$ & 4361 & $21 \pm 11$ & 23,861 & $20 \pm 10$ \\
\hline Hematocrit $(\%)$ & 3844 & $38 \pm 5.4$ & 21,046 & $39 \pm 5.4$ \\
\hline \multicolumn{5}{|l|}{ Procedure } \\
\hline Aortic valve & 4430 & $1299(29)$ & 24,272 & $5978(25)$ \\
\hline Mitral valve & 4430 & $1309(30)$ & 24,272 & $6602(27)$ \\
\hline Tricuspid valve & 4430 & $273(6.2)$ & 24,272 & $1124(4.6)$ \\
\hline No. of ITA grafts & 4430 & & 24,271 & \\
\hline 0 & & $2143(48)$ & & $10,498(43)$ \\
\hline 1 & & $2026(46)$ & & $11,672(48)$ \\
\hline 2 & & $261(5.9)$ & & $2101(8.7)$ \\
\hline CABG & 4430 & $3120(70)$ & 24,272 & $17,642(73)$ \\
\hline Surgical approach: less invasive incision & 4430 & $488(11)$ & 24,272 & $2781(11)$ \\
\hline \multicolumn{5}{|l|}{ Support } \\
\hline Cardiopulmonary bypass time (min) & 4430 & $96 \pm 47$ & 24,271 & $95 \pm 45$ \\
\hline \multicolumn{5}{|l|}{ Experience } \\
\hline Date of operation $(\mathrm{y}) \ddagger$ & 4430 & $6.2 \pm 3.4$ & 24,272 & $5.9 \pm 3.7$ \\
\hline
\end{tabular}

$S D$, Standard deviation; $B M I$, body mass index; NYHA, New York Heart Association; $E C G$, electrocardiogram; $L A D$, left anterior descending; $L C x$, left circumflex; $R C A$, right coronary artery; $L M T$, left main trunk; $C O P D$, chronic obstructive pulmonary disease; ITA, internal thoracic artery; $C A B G$, coronary artery bypass graft. *Patients with data available. $\dagger$ Fifty percent stenosis or more. $\ddagger$ Interval from January 1, 1995, to date of operation.

deviations resulted in the highest prevalence for infection, with $3.7 \%$ when cefuroxime was administered too early, that is, 75 minutes before incision; for administration after incision the prevalence of infection was $2.4 \%$.

A number of perioperative factors were associated with increased likelihood for postoperative sternal wound infection (Table E1). The following factors were associated overall for the cefuroxime group: diabetes $(P<0001)$, stroke $(P=.0003)$, prior myocardial infarction $(P=.0002)$, peripheral arterial disease $(P=.0002)$, longer preoperative length of stay $(P=.04)$, operative factors such as mitral valve procedure $(P<.0001)$, lower preoperative hematocrit $(P=.001)$, complete heart block $(P=.02)$, and more internal thoracic artery (ITA) grafts $(P<.0001)$. The preminimum phase risk factors for cefuroxime included history of chronic obstructive pulmonary disease (COPD) $(P<.0001)$ and higher blood urea nitrogen $(P=.0002)$. The post-minimum phase risk factors for cefuroxime included larger body mass index (BMI) $(P=.0002)$ and higher New York Heart Association class $(P=.005)$. 


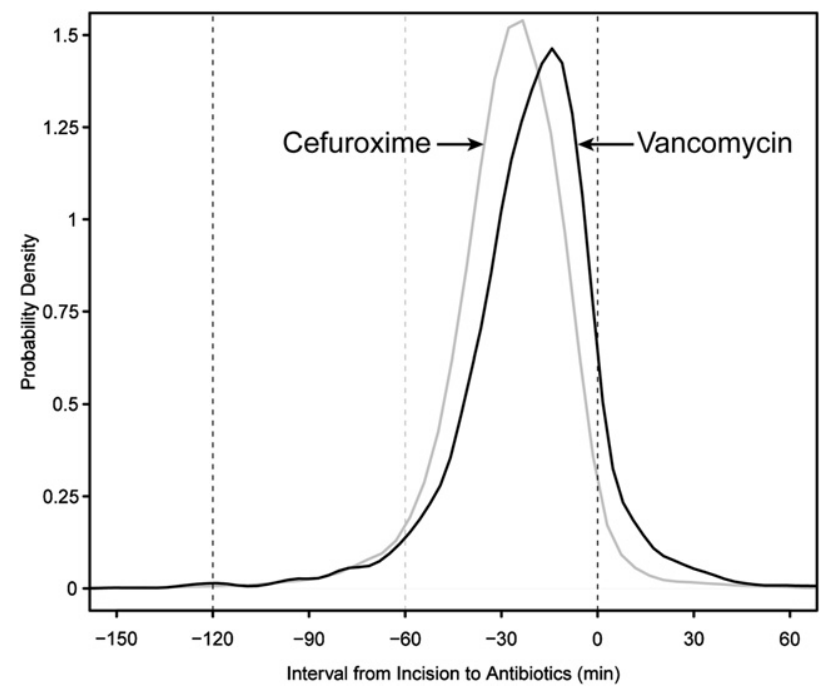

FIGURE 1. Distribution of antibiotic timing stratified by antibiotic status (cefuroxime, gray line; vancomycin, black line). Vertical dashed lines represent current protocol guidelines for administration.

Vancomycin. Antibiotic timing and likelihood for infection differed between vancomycin and cefuroxime. Unadjusted minimum prevalence of infection in patients who received vancomycin was $1.8 \%$ observed with antibiotic administration initiated 32 minutes before surgical incision (Figure 3). Predicted percentages for development of sternal wound infection varied considerably within protocol boundaries and for protocol deviations. Prevalence of infection was $2.2 \%$ for administration 45 minutes before incision: $3.2 \%$ with administration 60 minutes before incision and $4.6 \%$ with administration 75 minutes before incision. Vancomycin administration after incision resulted in a prevalence of infection of $3.3 \%$ (Table 2 and Figure 3 ).

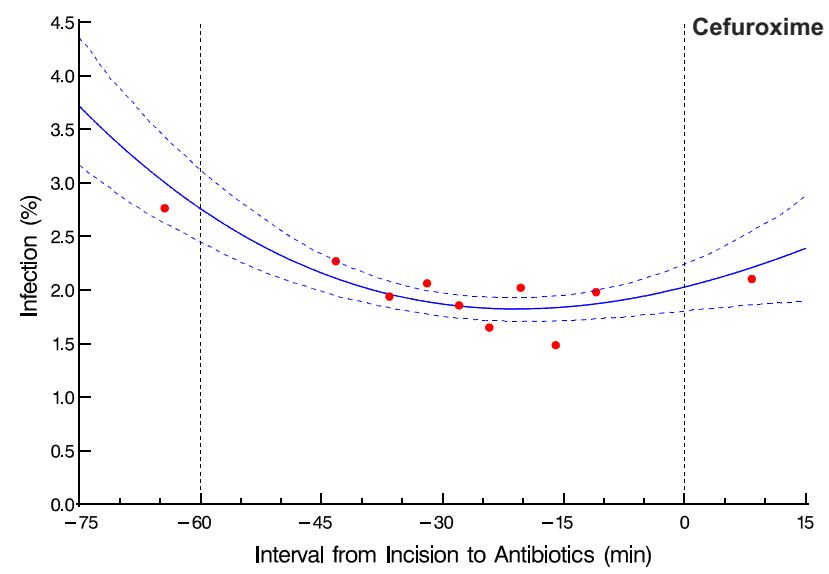

FIGURE 2. Percentage of postoperative sternal wound infections by time for cefuroxime antibiotic prophylaxis. Solid line represents estimated percentages of infection enclosed within dashed $68 \%$ bootstrapped percentile confidence intervals. Symbols represent data grouped within time frame to provide a crude verification of model fit. Vertical dashed lines represent current protocol time frame for administration.
TABLE 2. Predicted percentages of infection at different antibiotic timing administration for cefuroxime and vancomycin

\begin{tabular}{lcc}
\hline $\begin{array}{c}\text { Antibiotic } \\
\text { timing (min) }\end{array}$ & $\begin{array}{c}\text { Cefuroxime predicted \% } \\
(\mathbf{6 8} \% \mathbf{C L s})\end{array}$ & $\begin{array}{c}\text { Vancomycin predicted \% } \\
\mathbf{( 6 8} \% \mathbf{C L s})\end{array}$ \\
\hline-75 & $3.7(3.2-4.4)$ & $4.6(2.5-6.8)$ \\
-60 & $2.8(2.4-3.1)$ & $3.2(2.1-4.5)$ \\
-45 & $2.2(2.0-2.3)$ & $2.2(1.6-2.8)$ \\
-30 & $1.9(1.8-2.0)$ & $1.8(1.5-2.2)$ \\
-15 & $1.8(1.7-2.0)$ & $2.1(1.8-2.3)$ \\
0 (incision) & $2.0(1.8-2.2)$ & $2.6(2.1-3.0)$ \\
15 & $2.4(1.9-2.9)$ & $3.3(2.4-4.0)$ \\
\hline
\end{tabular}

CLs, Confidence limits.

Risk factors associated with a higher likelihood of wound infection in the vancomycin group (Table E2) were diabetes $(P=.007)$, history of chronic obstructive pulmonary disease $(P=.01)$, dialysis $(P=.03)$, coronary artery disease such as left anterior descending $(P=.01)$ or left main trunk disease $(P=.02)$, emergency operation $(P=.02)$, and no history of hypertension $(P=.02)$. The pre-minimum phase risk factor for vancomycin was bilateral ITA grafts $(P=.0001)$. The post-minimum phase risk factors for vancomycin were higher blood urea nitrogen $(P=.07)$ and larger BMI $(P=.04)$.

\section{Simulation and Optimal Timing}

Cefuroxime. Risk-adjusted optimal timing was defined as the time of antibiotic administration resulting in the lowest likelihood for postoperative sternal wound infection. Cefuroxime timing varied between 75 minutes before incision to the time of incision. Mean optimal risk-adjusted time for cefuroxime administration was 27 minutes ( \pm 14 minutes) before surgical incision. However, optimal timing was influenced by phase-specific risk factors. In patients with COPD, mean optimal timing was 18 minutes before incision versus those without COPD, for whom it was 30 minutes. Patients with greater BMI $\left(>30 \mathrm{~kg} \cdot \mathrm{m}^{-2}\right)$ had an optimal time of cefuroxime administration of 39 minutes versus

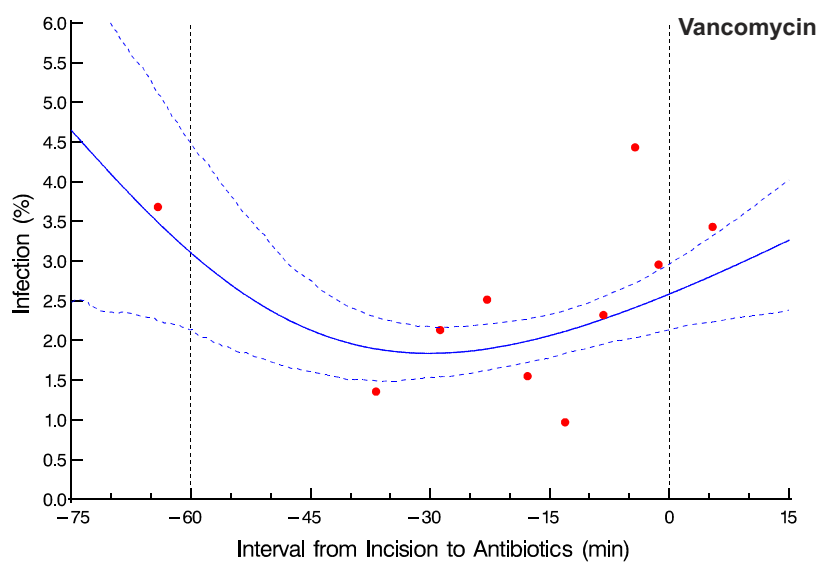

FIGURE 3. Percentage of postoperative sternal wound infections by time for vancomycin antibiotic prophylaxis. Format is as in Figure 2. 
TABLE 3. Risk-adjusted optimal cefuroxime timing and predicted reduction in sternal wound infection

\begin{tabular}{lccc}
\hline \multicolumn{1}{c}{ Group } & No. & $\begin{array}{c}\text { Optimal timing } \\
(\text { min, mean } \pm \text { SD) }\end{array}$ & $\begin{array}{c}\text { Predicted } \\
\text { reduction }(\%)\end{array}$ \\
\hline Overall & 24,034 & $-27 \pm 14$ & $46(9.5)$ \\
$\begin{array}{l}\text { Risk-adjusted individual } \\
\text { patient timing } \dagger\end{array}$ & - & - & $85(18)$ \\
COPD & & & $55(11)$ \\
$\quad$ No & 17,835 & $-30 \pm 12$ & \\
$\quad$ Yes & 6199 & $-18 \pm 13$ & \\
$\mathrm{BMI}$ & & & $60(12)$ \\
$\leq 30 \mathrm{~kg} \cdot \mathrm{m}^{-2}$ & 16,701 & $-21 \pm 10$ & \\
$>30 \mathrm{~kg} \cdot \mathrm{m}^{-2}$ & 7333 & $-39 \pm 11$ & \\
$\mathrm{COPD}$ and $\mathrm{BMI}$ & & & \\
$\mathrm{No} \mathrm{COPD}$ & & & \\
$\quad \mathrm{BMI} \leq 30 \mathrm{~kg} \cdot \mathrm{m}^{-2}$ & 12,500 & $-24 \pm 8.9$ & \\
$\quad \mathrm{BMI}>30 \mathrm{~kg} \cdot \mathrm{m}^{-2}$ & 5335 & $-43 \pm 10$ & \\
$\mathrm{COPD}$ & & & \\
$\quad \mathrm{BMI} \leq 30 \mathrm{~kg} \cdot \mathrm{m}^{-2}$ & 4201 & $-12 \pm 9.2$ & \\
$\mathrm{BMI}>30 \mathrm{~kg} \cdot \mathrm{m}^{-2}$ & 1998 & $-31 \pm 11$ & \\
\hline
\end{tabular}

$\overline{S D}$, Standard deviation; $C O P D$, chronic obstructive pulmonary disease; $B M I$, body mass index. *Predicted reduction in sternal wound infection when using optimal timing. †Based on individual risk-adjusted optimal timing (Figure E2)

those with a BMI of $30 \mathrm{~kg} \cdot \mathrm{m}^{-2}$ or less, for whom optimal time of administration was 21 minutes before incision. Optimal time of cefuroxime administration also differed with combinations of risk factors (Table 3 and Figure E2).

Using the mean risk-adjusted optimal timing of 27 minutes for administration of cefuroxime could result in a $9.5 \%$ reduction in postoperative sternal wound infection, and with consideration of individual optimal antibiotic timing related to patient-specific risk factors, reductions of up to $18 \%$ could be realized (see Table 3 ).

Vancomycin. Mean risk-adjusted optimal timing for vancomycin administration was 32 minutes before incision. Risk for sternal wound infection was similarly related to patient-specific factors. Simulation suggested a closer time for antibiotic administration to incision in patients with bilateral ITA grafting and greater time from vancomycin administration to incision (39 minutes) for patients with higher BMI (>30 $\mathrm{kg} \cdot \mathrm{m}^{-2}$ ) (Table 4 and Figure E3).

Overall percent reduction in the prevalence of postoperative sternal wound infection could be achieved with consideration of optimal antibiotic timing and patient-specific risk factors. For example, use of mean optimal vancomycin timing could result in an overall $18 \%$ reduction in postoperative sternal wound infection, and with consideration of patient-specific risk factors, a 31\% reduction in sternal wound infection could be achieved (see Table 4).

\section{COMMENT}

\section{Principal Findings}

Prevalence of postoperative sternal wound infection varied considerably when prophylactic administration was within standard protocol guidelines. Lowest observed
TABLE 4. Risk-adjusted optimal vancomycin timing and predicted reduction in sternal wound infection

\begin{tabular}{|c|c|c|c|}
\hline Group & No. & $\begin{array}{c}\text { Optimal timing } \\
(\text { min, mean } \pm \text { SD) }\end{array}$ & $\begin{array}{c}\text { Predicted } \\
\text { reduction }(\%)^{*}\end{array}$ \\
\hline Overall & 4356 & $-32 \pm 10$ & $18(18)$ \\
\hline $\begin{array}{l}\text { Risk-adjusted individual } \\
\text { patient timing } \dagger\end{array}$ & - & - & $30(31)$ \\
\hline Bilateral ITA & & & $27(28)$ \\
\hline No & 4100 & $-34 \pm 7.1$ & \\
\hline Yes & 256 & $-1.9 \pm 2.4$ & \\
\hline BMI & & & $18(18)$ \\
\hline$\leq 30 \mathrm{~kg} \cdot \mathrm{m}^{-2}$ & 2918 & $-29 \pm 8.2$ & \\
\hline$>30 \mathrm{~kg} \cdot \mathrm{m}^{-2}$ & 1438 & $-39 \pm 11$ & \\
\hline
\end{tabular}

prevalence for infection was administration to skin incision time of 19 minutes for cefuroxime and 32 minutes for vancomycin. Protocol deviations in antibiotic administration increased occurrence of sternal wound infections. By following mean optimal risk-adjusted timing of antibiotic administration, potential for reducing the likelihood of sternal wound infection was $9.5 \%$ with cefuroxime and $18 \%$ with vancomycin. Furthermore, when patient-specific risk factors were considered in antibiotic prophylaxis timing, opportunity for reducing postoperative sternal wound infection reached $18 \%$ for cefuroxime and $31 \%$ for vancomycin.

Recommendations for antimicrobial prophylaxis include antibiotic administration within 60 minutes of surgical incision for cephalosporins and within 120 minutes for vancomycin. Intent of guidelines in terms of proper timing of therapy is to allow time for adequate blood and tissue concentrations to exceed minimum inhibitory concentration of the pathogens, thereby preventing an infection at the surgical site. ${ }^{8,9}$ Published guidelines address both timing and duration of antimicrobial therapy in the surgical setting. ${ }^{10}$

An investigation of surgical site infections and antibiotics with shorter administration times reported a trend toward lower risk when cephalosporins were given within $30 \mathrm{~min}$ utes of (before) incision time. Infection risk increased as the time interval between preoperative antibiotic and incision increased or if antibiotic was administrated after skin incision. Infection risk after administration of antibiotic within 30 minutes before incision was $1.6 \%$ compared with $2.4 \%$ with administration between 31 to 60 minutes before incision. ${ }^{11}$ Their data suggested that optimal timing is perhaps closer to incision, similar to our findings.

In contrast, others have reported that cefuroxime administration immediately before surgical incision may be less effective than antimicrobial therapy given between 30 and 60 minutes of incision. ${ }^{12}$ Differences among reported studies may be related to patient-specific factors, such as obesity, and factors related to the surgical procedure, such as use of ITA grafting. 
Garey and colleagues ${ }^{13}$ examined timing of vancomycin prophylaxis and risk of surgical site infections in cardiac surgical patients. Vancomycin administration initiated within 16 to 60 minutes before surgical incision reduced the risk of surgical site infections. In a separate investigation, they demonstrated that optimizing vancomycin administration before surgical incision could lead to economic benefits by decreasing surgical site infections and subsequent length of hospital stay. ${ }^{14}$

\section{Risk Factors}

Reported prevalence of deep and superficial sternal wound infections after cardiac surgery range from $0.25 \%$ to $4 \%$ and $2 \%$ to $6 \%$, respectively. ${ }^{15-22}$ In coronary artery bypass grafting, Crabtree and colleagues reported a $2.2 \%$ prevalence of superficial and $1.8 \%$ prevalence of deep sternal wound infections. Risk factors for superficial infections were higher BMI, female gender, active smoking, use of bilateral ITA grafts, and transfusion. Risk factors for deep sternal wound infections included increasing BMI, diabetes, and platelet transfusion. ${ }^{20}$ Our investigation and others have similarly reported that patient demographics, comorbidity, and operative factors are related to an increased risk for developing sternal wound infections. ${ }^{18,19,23}$

\section{Clinical Implications}

Morbid complications related to sternal wound infections are significant, with mortality estimates of $5 \%$ to $23 \% .^{15,20,24,25}$ From STS data, Fowler and colleagues ${ }^{16}$ reported an overall $3.5 \%$ occurrence of major infection, among which $25 \%$ were due to mediastinitis $(0.6 \%$ overall). Patients with major postoperative infections had higher mortality and longer postoperative length of stay than patients without major infections. Braxton and colleagues similarly reported increased mortality in patients who developed mediastinitis following isolated coronary artery bypass grafting ${ }^{17}$ and, in a separate investigation, reported lower 1- and 4-year survival. ${ }^{26}$

Other investigators have suggested an opportunity to reduce occurrence of sternal wound infections by targeting patient-specific factors, such as weight reduction and smoking cessation. ${ }^{15}$ Our results offer additional opportunity for reducing infection by refining current guideline recommendations. The best we can do with perfect simulation is to determine whether antibiotic administration should be closer or further from skin incision to get the best results. We demonstrated a "U-shaped" relationship whereby risk for infection increased outside the recommended boundaries. The concept of optimal time exists only when the ideal is within some boundary limits, that is, either too early or too late. Why risk for infection increases when antibiotics are administered more than 60 minutes before incision is unclear, because antibiotic tissue levels should be sufficient until the next dosing interval (hours later). Our findings demonstrate that there may be an optimal time, yet also that patientspecific risk factors should be considered in this population.

Reality of findings about when to administer antibiotics suggests clinicians think about optimal antibiotic timing in the context of patient-specific risk factors. For example, in patients with higher BMI $\left(>30 \mathrm{~kg} \cdot \mathrm{m}^{-2}\right)$, simulation suggests a beneficial effect of shifting antibiotic administration to allow for more time between administration and incision, possibly allowing for adequate tissue antimicrobial activity. Limited pharmacokinetic studies have been performed in obese patients, for whom many factors may affect antimicrobial concentrations. Standard doses of cephalosporins may result in low serum and tissue levels in these patients; increasing cefazolin from 1 to $2 \mathrm{~g}$ has been reported to reduce their surgical site infections $(16 \%$ to $5.6 \%) .{ }^{27}$ Edmiston and colleagues ${ }^{28}$ examined patients undergoing open or laparoscopic gastric bypass who received cefazolin $2 \mathrm{~g}$ intravenously 30 to 60 minutes before incision and reported decreasing concentrations of cefazolin in the serum, skin, adipose tissue, and omental tissue with increasing BMI.

When considering patient-specific risk factors such as BMI, modifications in cefuroxime administration could reduce infection by $12 \%$. Similarly, with use of ITA grafting, special consideration in vancomycin antibiotic timing could result in reductions in the likelihood of infection by $28 \%$.

\section{Limitations}

Our primary outcome was development of deep and superficial wound infections identified during the primary hospitalization. Sternal wound infections becoming manifest after discharge were not included because longitudinal follow-up data for these were unavailable. Lack of this information underestimates occurrence of sternal wound infections. The Cardiothoracic Surgical Trials Network recently completed one of the first in-depth investigations on infectious complications after cardiac surgery. Patients were followed up to 60 days from index surgical procedure for development of infections. A number of postoperative infections occurred after discharge and varied depending on the individual infectious complications. Among patients in whom mediastinitis developed after surgery, approximately $50 \%$ were identified after discharge. ${ }^{29}$ Our sample is based on the data that we and the STS currently have available for reporting infectious complications. We believe that the infections are initiated in the perioperative period yet manifest either early or late. We do not have data to suggest that infections manifesting later after discharge are different from those manifesting in-hospital after the index surgery. We used STS rather than Center for Disease Control definitions for sternal wound infections. In addition, this investigation was a prospective cohort investigation, and unmeasured confounding variables could have affected study results. 


\section{CONCLUSIONS}

Sternal wound infections are a dreaded complication of cardiac surgery and portend serious morbidity. Patient safety depends on seizing the limited opportunity for control of preoperative risk. Our data demonstrate the importance of refining process-of-care factors such as antibiotic timing. Optimal timing with consideration of patientspecific risk factors reduced the likelihood of developing postoperative sternal wound infections.

\section{References}

1. Shrestha NK, Banbury MK, Weber M, Cwynar RE, Lober C, Procop GW, et al. Safety of targeted perioperative mupirocin treatment for preventing infections after cardiac surgery. Ann Thorac Surg. 2006;81:2183-8.

2. Duncan AE, Abd-Elsayed A, Maheshwari A, Xu M, Soltesz E, Koch CG. Role of intraoperative and postoperative blood glucose concentrations in predicting outcomes after cardiac surgery. Anesthesiology. 2010;112:860-71.

3. R Development Core Team. R: a language and environment for statistical computing. 2008. Available at: http://www.R-project.org.

4. Rubin DB. Multiple imputation for non-response in surveys. New York: Wiley; 1997.

5. Efron B, Tibshirani RJ. An introduction to the bootstrap. New York: Chapman and Hall/CRC; 1998.

6. Breiman L. Bagging predictors. Machine Learning. 1996;24:123-40.

7. Blackstone EH. Breaking down barriers: helpful breakthrough statistical methods you need to understand better. J Thorac Cardiovasc Surg. 2001;122: 430-9.

8. Bratzler DW, Houck PM. Antimicrobial prophylaxis for surgery: an advisory statement from the National Surgical Infection Prevention Project. Clin Infect Dis. 2004;38:1706-15.

9. Kitzes-Cohen R, Farin D, Piva G, Ivry S, Sharony R, Amar R, et al. Pharmacokinetics of vancomycin administered as prophylaxis before cardiac surgery. Ther Drug Monit. 2000;22:661-7.

10. Edwards FH, Engelman RM, Houck P, Shahian DM, Bridges CR. The Society of Thoracic Surgeons Practice Guideline Series: Antibiotic Prophylaxis in Cardiac Surgery, Part I: Duration. Ann Thorac Surg. 2006;81:397-404.

11. Steinberg JP, Braun BI, Hellinger WC, Kusek L, Bozikis MR, Bush AJ, et al. Timing of antimicrobial prophylaxis and the risk of surgical site infections: results from the Trial to Reduce Antimicrobial Prophylaxis Errors. Ann Surg. 2009;250:10-6

12. Weber WP, Marti WR, Zwahlen M, Misteli H, Rosenthal R, Reck S, et al. The timing of surgical antimicrobial prophylaxis. Ann Surg. 2008;247:918-26.

13. Garey KW, Dao T, Chen H, Amrutkar P, Kumar N, Reiter M, et al. Timing of vancomycin prophylaxis for cardiac surgery patients and the risk of surgical site infections. J Antimicrob Chemother. 2006;58:645-50.
14. Garey KW, Amrutkar P, Dao-Tran TK, Frost CP, Chen H, Essien EJ, et al. Economic benefit of appropriate timing of vancomycin prophylaxis in patients undergoing cardiovascular surgery. Pharmacotherapy. 2008;28:699-706.

15. Abboud CS, Wey SB, Baltar VT. Risk factors for mediastinitis after cardiac surgery. Ann Thorac Surg. 2004;77:676-83.

16. Fowler VG Jr, O'Brien SM, Muhlbaier LH, Corey GR, Ferguson TB, Peterson ED. Clinical predictors of major infections after cardiac surgery. Circulation. 2005;112(9 Suppl):I358-65.

17. Braxton JH, Marrin CA, McGrath PD, Morton JR, Norotsky M Charlesworth DC, et al. 10-year follow-up of patients with and without mediastinitis. Semin Thorac Cardiovasc Surg. 2004;16:70-6.

18. Risnes I, Abdelnoor M, Almdahl SM, Svennevig JL. Mediastinitis after coronary artery bypass grafting: risk factors and long-term survival. Ann Thorac Surg. 2010;89:1502-9

19. Baskett RJ, MacDougall CE, Ross DB. Is mediastinitis a preventable complication? A 10-year review. Ann Thorac Surg. 1999;67:462-5.

20. Crabtree TD, Codd JE, Fraser VJ, Bailey MS, Olsen MA, Damiano RJ Jr. Multivariate analysis of risk factors for deep and superficial sternal infection after coronary artery bypass grafting at a tertiary care medical center. Semin Thorac Cardiovasc Surg. 2004; 16:53-61.

21. Olsen MA, Lock-Buckley P, Hopkins D, Polish LB, Sundt TM, Fraser VJ. The risk factors for deep and superficial chest surgical-site infections after coronary artery bypass graft surgery are different. J Thorac Cardiovasc Surg. 2002;124: 136-45.

22. Ridderstolpe L, Gill H, Granfeldt H, Ahlfeldt H, Rutberg H. Superficial and deep sternal wound complications: incidence, risk factors and mortality. Eur J Cardiothorac Surg. 2001;20:1168-75.

23. De Paulis R, de Notaris S, Scaffa R, Nardella S, Zeitani J, Del Giudice C, et al. The effect of bilateral internal thoracic artery harvesting on superficial and deep sternal infection: the role of skeletonization. J Thorac Cardiovasc Surg. 2005; 129:536-43

24. Demmy TL, Park SB, Liebler GA, Burkholder JA, Maher TD, Benckart DH, et al Recent experience with major sternal wound complications. Ann Thorac Surg. 1990;49:458-62.

25. Tang GH, Maganti M, Weisel RD, Borger MA. Prevention and management of deep sternal wound infection. Semin Thorac Cardiovasc Surg. 2004;16:62-9.

26. Braxton JH, Marrin CA, McGrath PD, Ross CS, Morton JR, Norotsky M, et al. Mediastinitis and long-term survival after coronary artery bypass graft surgery. Ann Thorac Surg. 2000;70:2004-7.

27. Forse RA, Karam B, MacLean LD, Christou NV. Antibiotic prophylaxis for surgery in morbidly obese patients. Surgery. 1989;106:750-7.

28. Edmiston CE, Krepel C, Kelly H, Larson J, Andris D, Hennen C, et al. Perioperative antibiotic prophylaxis in the gastric bypass patient: do we achieve therapeutic levels? Surgery. 2004;136:738-47.

29. Acker M, Argenziano M, Puskas J, Ferguson B, Gelijns A, Horvath K, et al. Infections after cardiac surgery: initial experience from the Cardiothoracic Surgical Trials Network (abstract). Presented at: the 2011 American Heart Association annual meeting; November 12-16, 2011; Orlando, FL. 


\section{APPENDIX E1.}

\section{Nonlinear Multivariable Logistic Regression}

We have used a 2-step modeling strategy to quantify the relationship between timing of antibiotic administration and infection and baseline patient-procedure characteristics and infection. In the first step, because the descriptive investigations revealed a skewed U-shaped relationship between timing of antibiotic administration and infection, we used additive nonlinear equations and logistic regression to identify the decreasing and increasing phases (of timing of antibiotics). We call these pre-minimum and post-minimum phases.

It is believed that there may be some baseline variables that influence (or in other words, interact with the timing of antibiotics) the infection only in the pre-minimum phase, some only in the post-minimum phase, and some independently of the phases (of the timing of antibiotics). Hence, in the second step, we performed multivariable logistic regression simultaneously to identify the 3 sets of patientprocedure characteristics. The motivation for this analytical strategy was similar to that used by Blackstone, Naftel, and Turner $^{\mathrm{E} 1}$ to model the time-related phases of hazard of time-to-event data.

\section{E-Reference}

E1. Blackstone EH, Naftel DC, Turner ME Jr. The decomposition of time-varying hazard into phases, each incorporating a separate stream of concomitant information. J Am Stat Assoc. 1986;81:615-24.

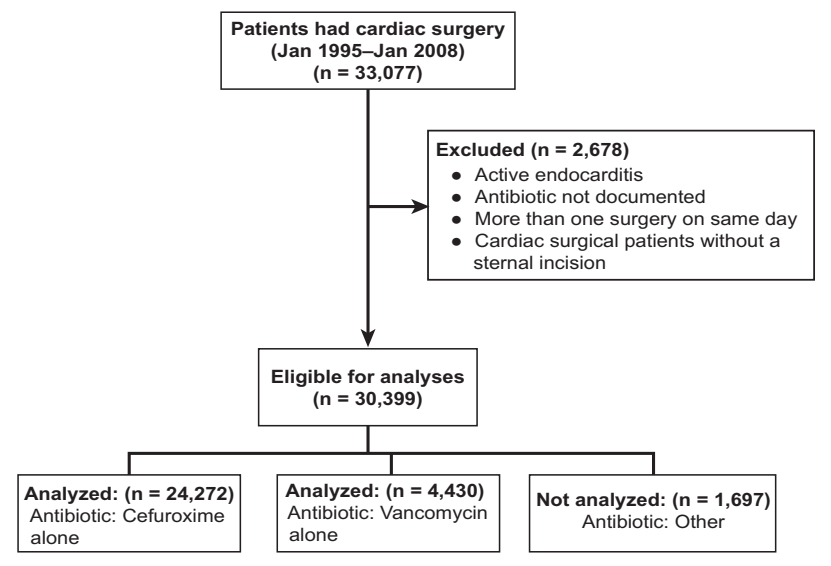

FIGURE E1. CONSORT diagram of patient population. 

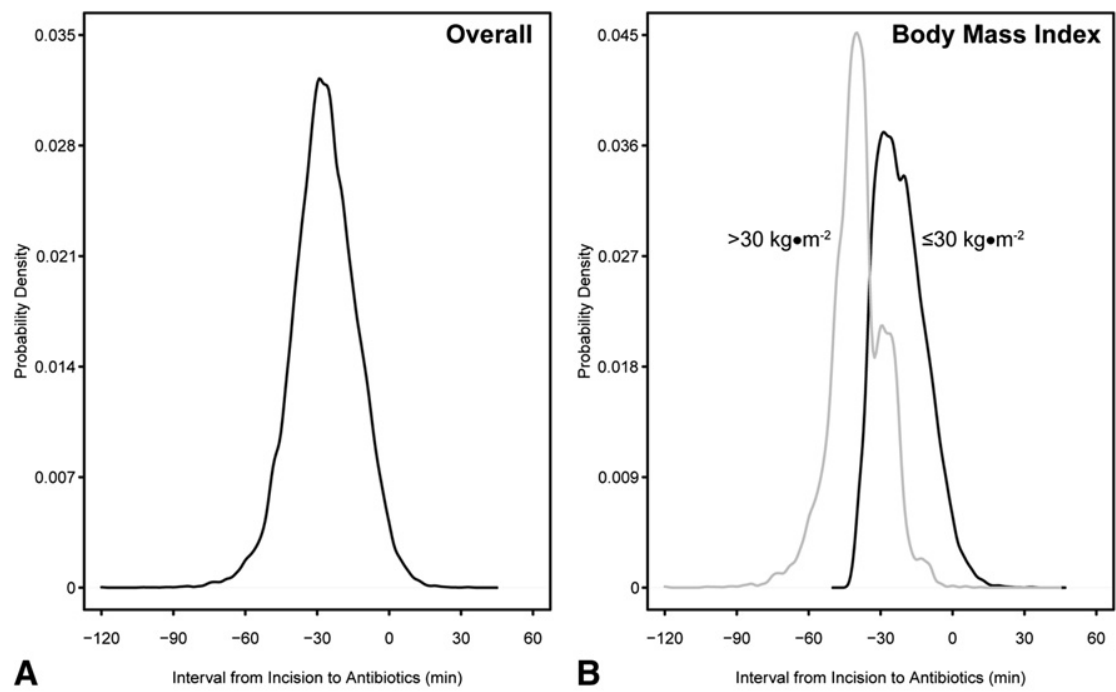

A

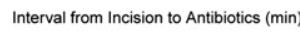

B
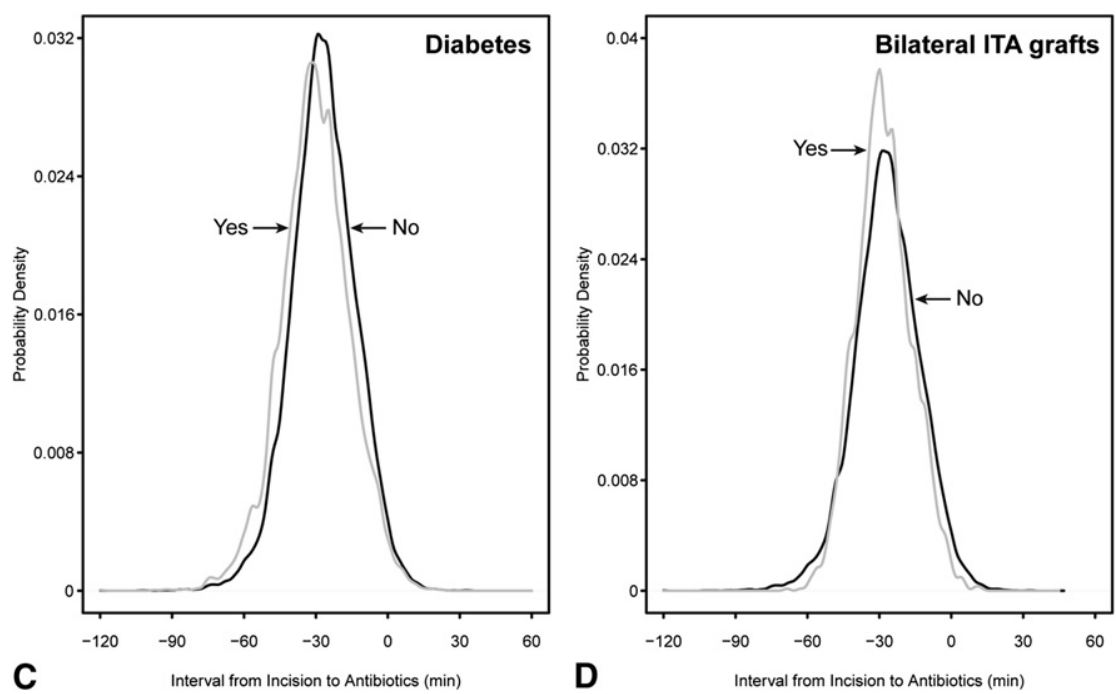

FIGURE E2. Distribution of patient-specific optimal timing in cefuroxime group. A, Overall; B, body mass index; C, diabetes; and D, bilateral ITA grafts. ITA, Internal thoracic artery. 

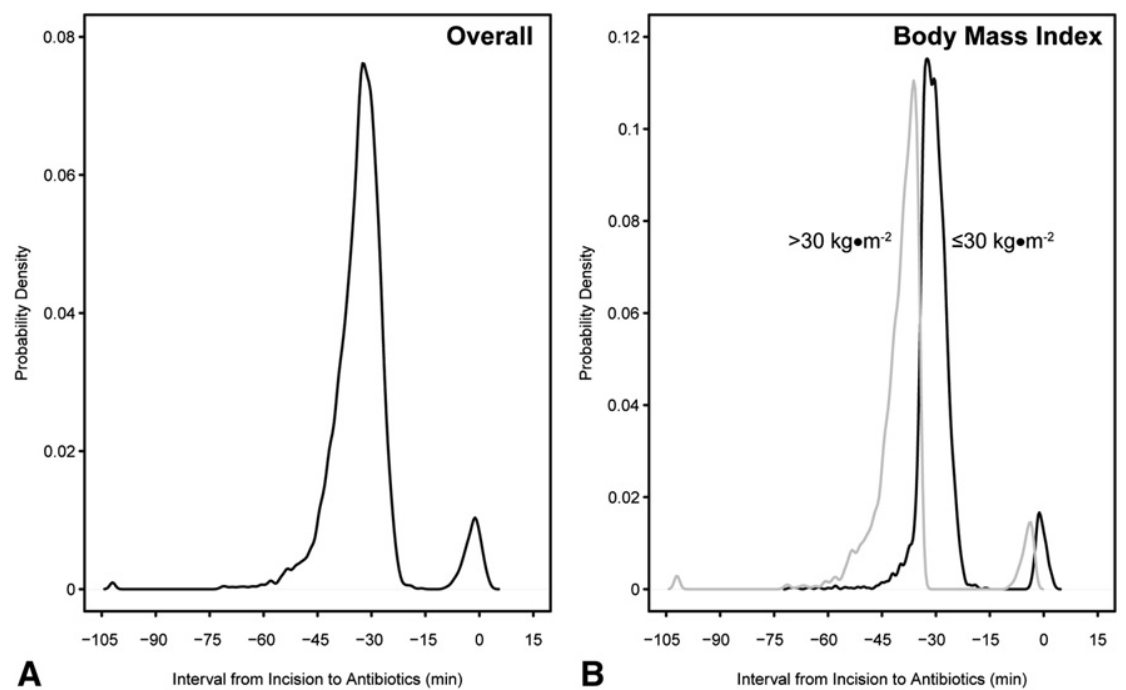

A

Interval from Incision to Antibiotics ( $\mathrm{min}$ )

B

Interval from Incision to Antibiotics ( $\mathrm{min}$ )
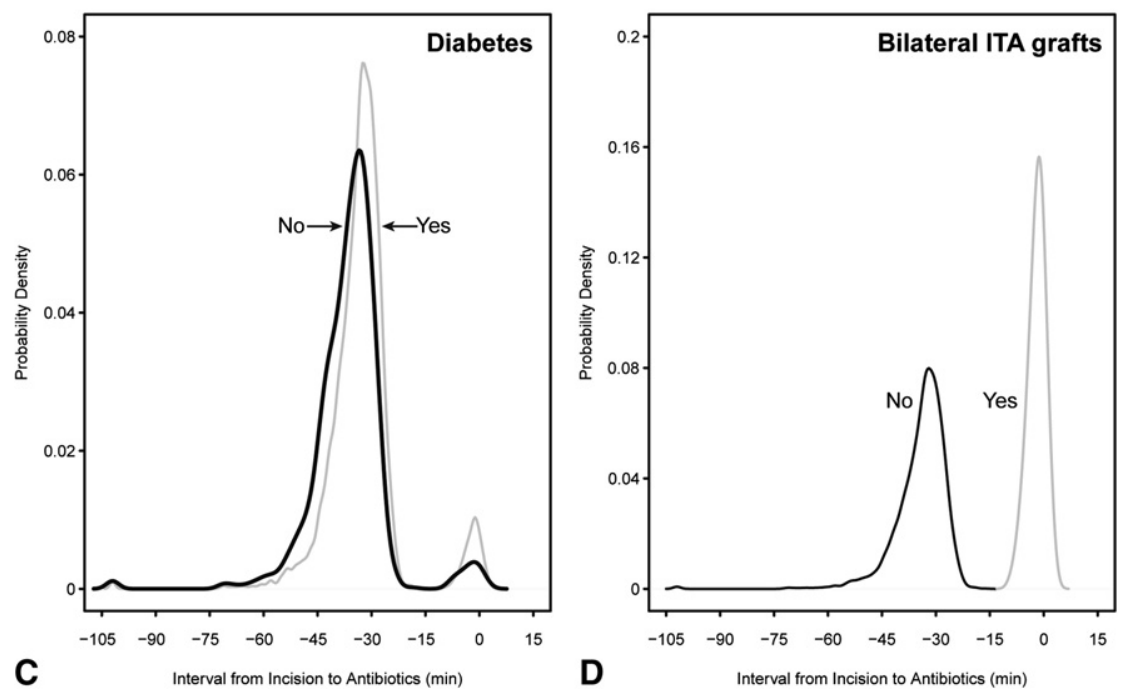

FIGURE E3. Distribution of patient-specific optimal timing in vancomycin group. A, Overall; B, body mass index; C, diabetes; D, bilateral ITA grafts. ITA, Internal thoracic artery. 
TABLE E1. Risk factors associated with higher likelihood of wound infection: cefuroxime group

\begin{tabular}{|c|c|c|c|}
\hline Factor & Estimate $\pm \mathrm{SE}$ & $\boldsymbol{P}$ & $\begin{array}{c}\text { Reliability } \\
(\%)^{*}\end{array}$ \\
\hline \multicolumn{4}{|l|}{ Overall } \\
\hline Diabetes & $0.52 \pm 0.100$ & $<.0001$ & 94 \\
\hline History of PAD & $0.32 \pm 0.099$ & .001 & 46 \\
\hline Previous stroke & $0.46 \pm 0.13$ & .0006 & 87 \\
\hline Lower hematocrit $\dagger$ & $12 \pm 3.5$ & .001 & 82 \\
\hline Longer preoperative LOS $\ddagger$ & $0.11 \pm 0.049$ & .02 & 66 \\
\hline Complete heart block/pacer & $0.45 \pm 0.203$ & .02 & 51 \\
\hline Previous MI & $0.33 \pm 0.101$ & .0009 & 86 \\
\hline Higher number of ITA grafts & $0.46 \pm 0.085$ & $<.0001$ & 100 \\
\hline Mitral valve procedure & $0.55 \pm 0.11$ & $<.0001$ & 100 \\
\hline \multicolumn{4}{|l|}{ Pre-minimum phase } \\
\hline History of COPD & $0.78 \pm 0.18$ & $<.0001$ & 73 \\
\hline Higher BUN $\S$ & $0.069 \pm 0.021$ & .001 & 86 \\
\hline \multicolumn{4}{|l|}{ Post-minimum phase } \\
\hline Larger BMI || & $0.79 \pm 0.11$ & $<.0001$ & 76 \\
\hline $\begin{array}{l}\text { Higher NYHA functional } \\
\text { class } \uparrow\end{array}$ & $-0.26 \pm 0.099$ & .009 & 90 \\
\hline \multicolumn{4}{|c|}{ 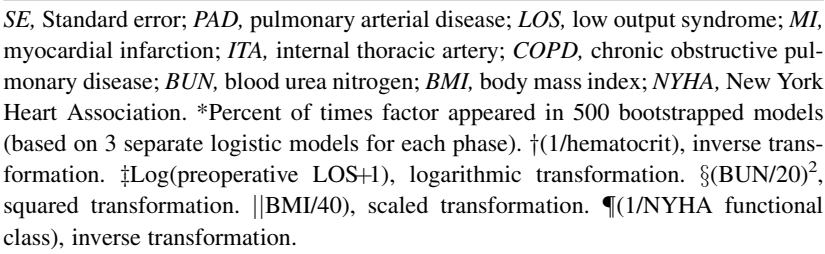 } \\
\hline
\end{tabular}

TABLE E2. Risk factors associated with higher likelihood of wound infection: vancomycin group

\begin{tabular}{lclc}
\hline \multicolumn{1}{c}{ Factor } & Estimate \pm SE & $\boldsymbol{P}$ & $\begin{array}{c}\text { Reliability } \\
(\%)^{*}\end{array}$ \\
\hline Overall & & & \\
$\quad$ Diabetes & $0.61 \pm 0.23$ & .007 & 84 \\
History of COPD & $0.57 \pm 0.23$ & .01 & 67 \\
Dialysis & $1.2 \pm 0.55$ & .03 & 84 \\
Coronary artery disease $\dagger$ & & & \\
$\quad$ LAD & $1.3 \pm 0.53$ & .01 & 94 \\
$\quad$ LMT & $0.55 \pm 0.23$ & .02 & 94 \\
Emergency operation & $1.3 \pm 0.47$ & .02 & 66 \\
$\quad$ No history of hypertension & $-0.60 \pm 0.26$ & .02 & 61 \\
Pre-minimum phase & & & \\
$\quad$ Bilateral ITA grafts & $2.7 \pm 0.71$ & .0001 & 81 \\
Post-minimum phase & & & \\
$\quad$ Higher BUN $\ddagger$ & $0.025 \pm 0.014$ & .07 & 83 \\
Larger BMI $\S$ & $0.75 \pm 0.36$ & .04 & 94 \\
\hline
\end{tabular}

$S E$, Standard error; $C O P D$, chronic obstructive pulmonary disease; $L A D$, left anterior descending; $L M T$, left main trunk; ITA, internal thoracic artery; $B U N$, blood urea nitrogen; $B M I$, body mass index. *Percent of times factor appeared in 500 bootstrapped

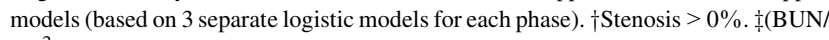
$20)^{2}$, squared transformation. $\S(\mathrm{BMI} / 40)$, scaled transformation. 